\title{
Chromosome in situ suppression hybridisation in human male meiosis
}

\author{
A S H Goldman, M A Hultén
}

\begin{abstract}
Chromosome in situ suppression hybridisation with biotinylated whole chromosome libraries permits the unequivocable identification of specific human somatic chromosomes in numerous situations. We have now used this so called 'chromosome painting' technique in meiotically dividing cells, isolated from human testicular biopsy. It is shown that the method allows identification of target homologues, bivalents, and sister chromatids throughout the relevant stages of meiosis. Thus, a more accurate study of meiosis per se is now available to increase our understanding of such processes as first meiotic synapsis of homologues and chiasma formation/meiotic crossing over, which are still outstanding biological enigmas. The new technology also makes it possible, for the first time, (1) to obtain direct numerical data in first meiotic non-disjunction for individual chromosomes, and (2) to quantify segregation in male carriers of structural rearrangements. We exemplify the use of the chromosome painting technique for a first meiotic segregation analysis of an insertional translocation carrier.
\end{abstract}

Improvements in in situ hybridisation have in recent years been exploited for the identification of individual human chromosomes by so called 'chromosome in situ suppression hybridisation (CISS)' or 'chromosome painting'. ${ }^{2}$ The technique, which allows delineation of the individual target homologues, uses biotin labelled whole chromosome libraries constructed originally from flow sorted chromosomes in combination with unlabelled human genomic DNA. ${ }^{34}$

This method has now been used in various situations. These include the identification of human chromosomal material in human/ rodent somatic cell hybrids, ${ }^{15-8}$ detection of structural abnormalities in tumour cell lines, ${ }^{9-11}$ identification of radiation induced chromosome damage, ${ }^{1213}$ investigation of the three dimensional organisation of chromosomes in interphase nuclei, ${ }^{514-17}$ and the labelling of $Y$ chromosomes in decondensed human sperm nuclei. ${ }^{18}$ None of the above, however, concerns meiotically dividing chromosomes.

The identification of human meiotic chromosomes at metaphase has, to date, relied upon complicated serial staining combining banding techniques such as distamycin-DAPI, $Q$ banding and $C$ banding with orcein or Giemsa block staining. ${ }^{19}$ This process is time consuming and is restricted practically to first metaphase bivalents since the poor morphology of second metaphase chromosomes presents serious limitations. This situation has been dramatically improved by the use of biotinylated whole chromosome libraries to 'paint' meiotic preparations as illustrated here. We find that the painting technique provides a rapid (overnight) method of identifying chromosome domains throughout spermatogenesis, from premeiotic spermatogonial metaphases through to sperm heads.

\section{Materials and methods}

SAMPLE PREPARATION

Testicular material was obtained from a 78 year old man who underwent a unilatera orchidectomy and a 35 year old man, the heterozygous carrier of a translocational insertion $(6 ; 7)$. Meiotic slides were prepared directly according to Hultén et al. ${ }^{19}$ These were stored in air at $70^{\circ} \mathrm{C}$ for up to eight months Before hybridisation the slides were screened under phase contrast to identify in particular late pachytene and metaphase nuclei.

PROBES

Chromosome libraries were prepared from host cell lines containing Bluescribe plasmid vectors for libraries pBS1, pBS4, pBS6, pBS7, pBS13, and pBS21. Vector plus insert DNA was digested to a size range of $<0.5$ to $2 \mathrm{~kb}$. This was followed by incubation of $3 \mu \mathrm{g}$ DNA for 90 minutes at $15^{\circ} \mathrm{C}$ in the presence of DNA polymerase $I$ and a nucleotide mixture con taining biotin-16-dUTP. The DNA was used directly from the nick translation mixture without separation of unincorporated nucleotides.

\section{IN SITU HYBRIDISATION}

This was carried out with slight modifications to the technique, 'protocol 1', of Pinkel et al. ${ }^{12}$ Thus, the total hybridisation mixture consisted of 3 to $9 \mathrm{ng} \mu \mathrm{I}^{-1}$ of biotinylated DNA, 67 to $500 \mathrm{ng} \mu \mathrm{l}^{-1}$ of sonicated human placental DNA, $50 \%$ formamide, $2 \times$ SSC (final concentrations). Before hybridisation the denatured hybridisation mixture was incubated for one hour at $37^{\circ} \mathrm{C}$. The slides were denatured for two minutes in $70 \%$ formamide $/ 2 \times \mathrm{SSC}$ and rapidly immersed in cold $70 \%$ ethanol followed by a serial dehydration in $80 \%$ and $100 \%$ ethanol (two minutes each). They were then dried in an air jet and prewarmed to $37^{\circ} \mathrm{C}$ before application of the hybridisation mixture. 

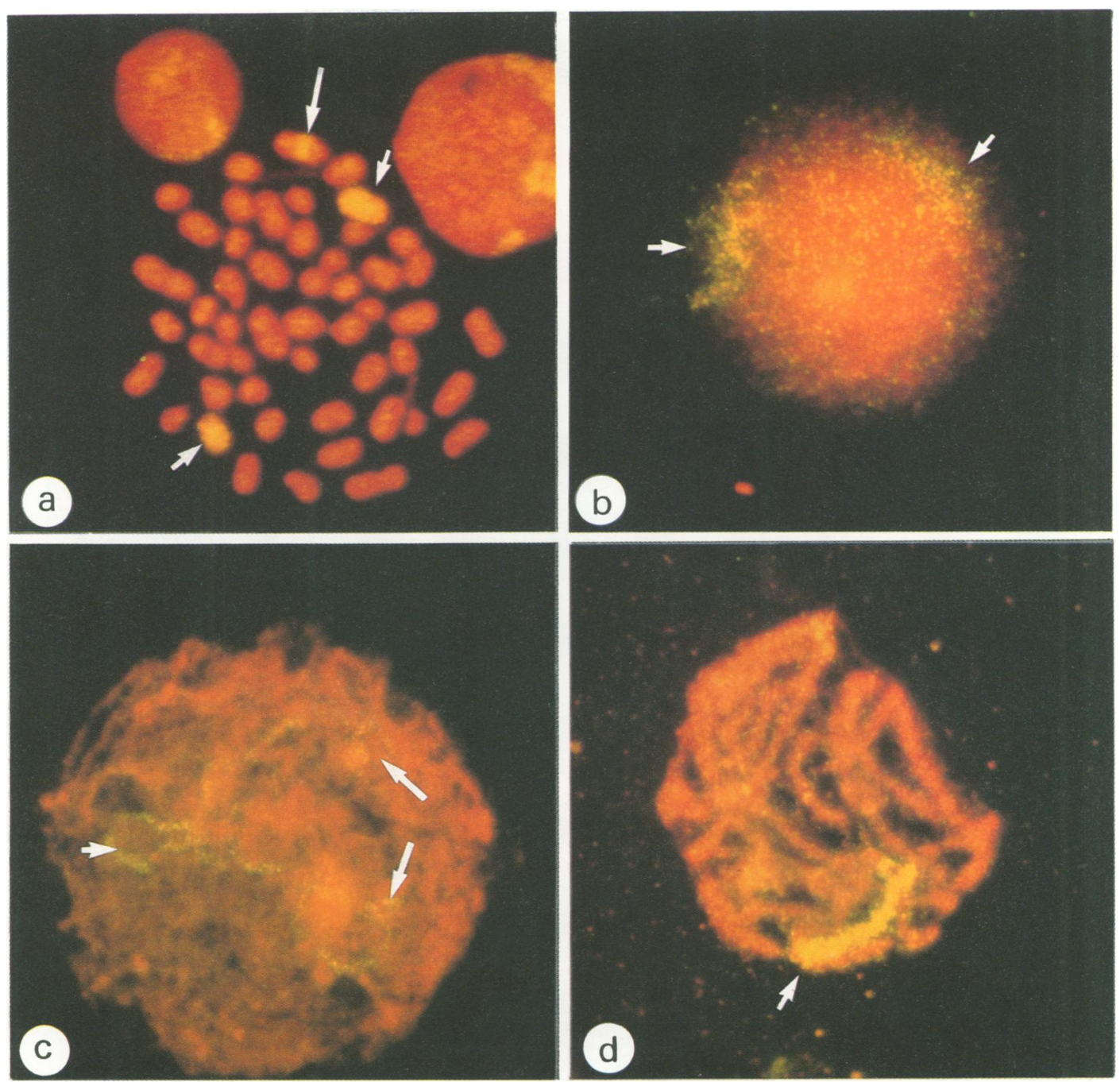

Figure 1 (a) Spermatogonial metaphase from a heterozygous carrier of a translocational insertion (6;7) hybridised with the chromosome 6 library. Both normal and deleted homologues of chromosome 6 are painted (short arrows) and the inserted material, translocated from the deleted 6 into a chromosome 7 homologue, is clearly distinguishable (long arrow). (b) Leptotene from a normal male hybridised with the chromosome 6 library. The two domains of hybridisation indicate the chromosome 6 homologues condensing at this stage (arrows). (c) Zygotene from a normal male hybridised with the chromosome 6 library. The yellow tract is thought to represent unpaired homologues undergoing pairing initiation (short arrow), with attachment plaques visible (long arrows). (d) Pachytene from a normal male hybridised with the chromosome 13 library. Bivalent 13 is arrowed.

POSTHYBRIDISATION

The slides were washed in three changes of $50 \%$ formamide $/ 2 \times \mathrm{SSC}, 2 \times \mathrm{SSC}, \mathrm{PN}$ (0.1 mol/1 phosphate buffer, $\mathrm{pH} 8$, containing $0.05 \% \mathrm{NP}-40$ ) and PNM (PN plus $5 \%$ non-fat dried milk) each for 10 minutes at $45^{\circ} \mathrm{C}$. Fluorescein conjugation was carried out according to Pinkel et al, ${ }^{12}$ applying either two or three layers of fluorescein avidin (DCS) and counter staining with propidium iodide $(0.5$ to $1 \mu \mathrm{g} \mathrm{ml}^{-1}$ ) in glycerol containing $250 \mu \mathrm{g} \mathrm{ml}^{-1}$ 1,4-diazabicylooctane (DABCO) 'anti-fade'.

MICROSCOPY/PHOTOGRAPHY

A Zeiss standard photomicroscope in combination with fluorescence filter set No 09 was used to view fluorescein and propidium iodide simultaneously. Fujichrome 400 ASA film was used, rated at 1400 ASA for exposure, but developed normally.

\section{Results and discussion}

The chromosome libraries used (for homologues $1,4,6,7,13$ and 21) hybridised to the target at all recognisable stages of spermatogenesis. In other words chromosome domains were readily visualised from premeiotic spermatogonial metaphase through the meiotic stages of leptotene, zygotene, pachytene, diakinesis/first metaphase, and second metaphase as well as in postmeiotic spermatids and sperm heads (figs 1 and 2). Each stage is described in more detail below.

\section{SPERMATOGONIAL METAPHASE}

Spermatogonial cells divide mitotically before the onset of meiosis. Three categories of spermatogonial metaphase cells were found as defined by chromosome length and morpho$\operatorname{logy} .^{2021}$ The metaphase nucleus illustrated in fig la was taken from a constitutional carrier of 

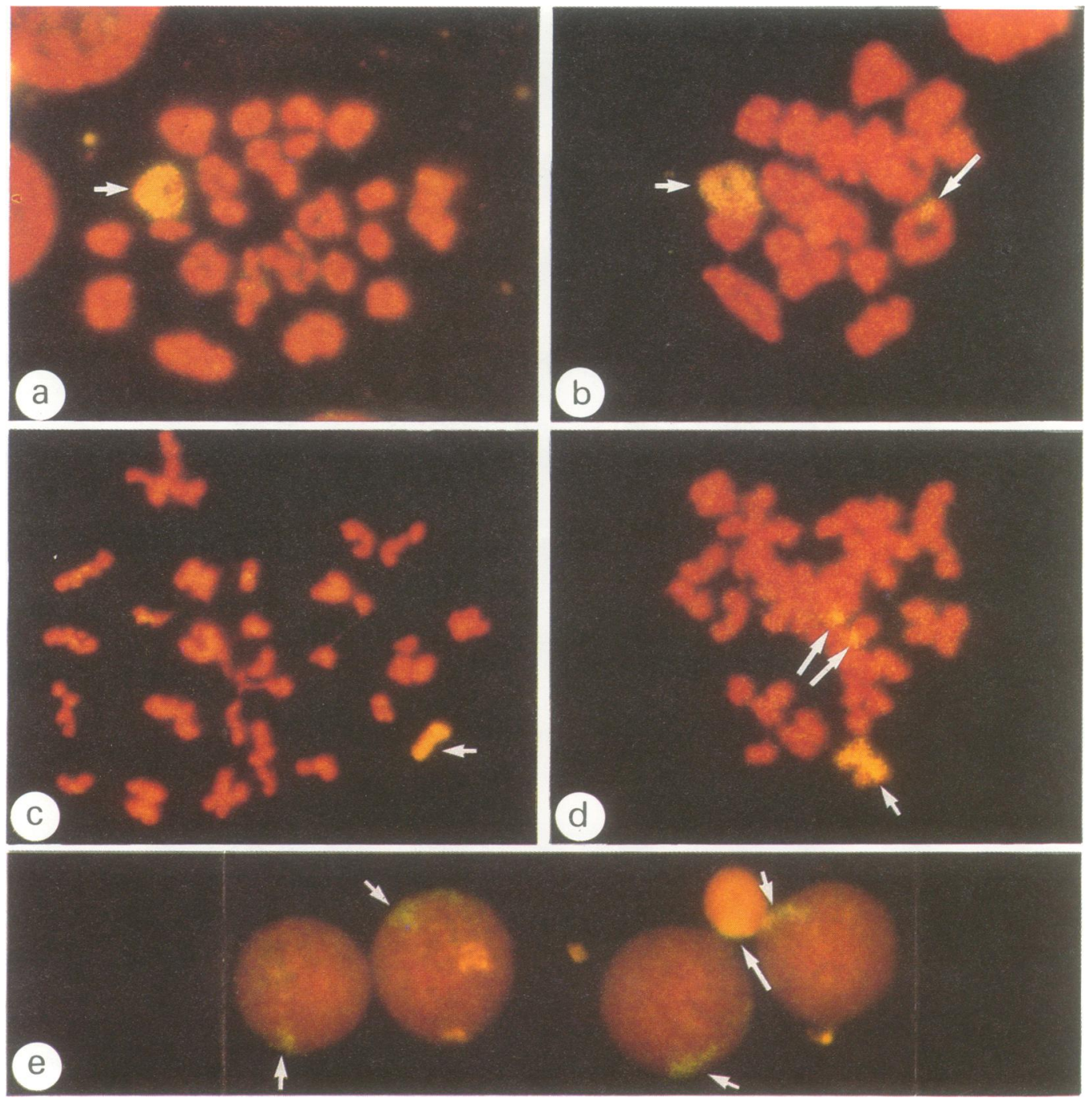

Figure 2 (a) Diakinesis/first metaphase from a normal male hybridised with the chromosome 6 library. Bivalent 6 is arrowed. (b) Diakinesis/first metaphase from a male heterozygous carrier of a translocational insertion (6;7) hybridised with the chromosome 6 library. Both bivalent 6 (short arrow) and bivalent 7 with one homologue bearing the insertion from chromosome 6 (long arrow) are identified. (c) Second metaphase from a normal male showing hybridisation of chromosome 6 (arrow). (d) Second metaphase from a male heterozygous carrier of a translocational insertion (6;7) hybridised with the chromosome 6 library. Chromosome 6 (short arrow) and a chromosome 7 bearing the insertion from chromosome 6 on each sister chromatid (long arrows) are identified. (e) Spermatids (short arrows) and a sperm head (long arrow) from a normal male hybridised with the chromosome 6 library. Each of these haploid cells exhibits a single domain.

a translocational insertion $(6 ; 7)$ and shows the short morphology where the chromosomes are too condensed for conventional high resolution banding. The fluorescence in situ hybridisation allows identification of not only the deleted and normal homologues of chromosome 6 but also visible is the modified chromosome 7 which contains the insertion from chromosome 6 (long arrow, fig 1a). This illustrates a potential use of chromosome painting in investigating, for example, gonadal mosaicism which may be a significant source of apparent de novo structural and numerical aberrations.

\section{LEPTOTENE/ZYGOTENE}

These two stages represent the condensation/ reorganisation of chromatin and pairing initiation of homologues. It is not possible, by triple staining of air dried preparations, to identify specific chromosome domains at these early stages of first prophase. In contrast, by use of this in situ hybridisation technology specific chromosome domains are resolvable. The cells interpreted as leptotene and zygotene show the major difference in chromatin organisation between the two stages. The leptotene cell (fig 1b) shows two clear domains, representing the bulk of chromosome 6 material in the nucleus. The zygotene cell, however (fig 1c), displays thin organised tracts of chromatin. Sites of pairing initiation (short arrow) and attachment plaques to the nuclear membrane (long arrows) are visible. More detailed information on pairing initiation and propagation will become available with the coupling of chromosome painting with the use of confocal microscopy. ${ }^{51617}$

\section{PACHYTENE}

By this stage homologues are fully paired along their entire length. The chromosome libraries show the arrangement of target bivalents relative to the rest of the genome. Thus, bivalent 13 
is clearly distinguishable in fig $1 \mathrm{~d}$. Investigating structural rearrangements in this manner will provide useful topological information complementing that obtained by surface spreading and serial EM reconstructions. ${ }^{1922}$

\section{DIAKINESIS/FIRST METAPHASE}

These cells contain bivalents which, in vivo, are arranged with each homologue co-orientated ready for segregation to opposite poles. Use of the highly specific chromosome 6 library on diakinesis/first metaphase cells is illustrated in a cell from a normal subject (fig $2 a$ ) and in a cell from the insertion $(6 ; 7)$ carrier (fig $2 b$ ). The ability to visualise such rearranged mater$\mathrm{ial}$ in these cells (long arrow, fig $2 \mathrm{~b}$ ) provides rapid identification of the rearranged chromosome.

\section{SECOND METAPHASE}

This stage, after the first meiotic division, represents cells with a haploid number of chromosomes preparing for the separation of sister chromatids to opposite poles. The morphology of second metaphase chromosomes is well known to be prohibitive to classical identification. Successful triple staining at this stage has been reported only once ${ }^{23}$ and information on the normal rate of first meiotic nondisjunction in man is extremely limited. The painting technology allows identification of individual chromosomes in second metaphase (fig $2 c$,d) even when nuclei are poorly spread, inhibiting a simple count of the total chromosome number. Rates of first meiotic non-disjunction in the human male may now be more readily obtained. Further, direct first meiotic segregation data become available for carriers of structural rearrangements for the first time. Thus, in the case of the heterozygous carrier of a translocational insertion $(6 ; 7)$ it is now possible to count the number of second metaphase cells inheriting the normal chromosome 7 compared to the chromosome 7 with insert from chromosome 6 (long arrows, fig 2d). Out of 132 second metaphases analysed, 63 were seen to contain the insertion, while 67 did not. These first meiotic segregation data do not significantly differ from the $50 \%$ theoretically expected.

\section{SPERMATIDS/SPERM HEADS}

These haploid cells represent the daughter cells of meiosis and the final differentiated products of spermatogenesis. Hybridisation continues to be efficient in these stages and it is noteworthy that, while a full statistical analysis has not been carried out, we find signs of hybridisation in close to $100 \%$ of sperm heads in our tissue preparations even though there has been no decondensation of these nuclei. ${ }^{182425} \mathrm{~A}$ single domain is expected in each cell for any autosomal chromosome. None or two could indicate aneuploidy arising from a previous non-disjunction event. This simple assay cannot, however, be reliably applied using whole chromosome libraries. While single domains are apparently seen in the spermatids and sperm head in fig $2 e$ (arrows) it is not possible to discern between a single domain and two either touching or close to each other. Further, no hybridisation could indicate poor probe penetration in these tightly packed nuclei (particularly in the sperm heads) rather than nullisomy. ${ }^{24} 25$ The problem of delineating interphase chromosome domains with this technology and improvements made with the use of confocal microscopy have been documented previously..$^{2514-18}$ Single site repetitive markers such as centromere specific probes will be more useful for direct studies of meiotic non-disjunction in spermatids and sperm heads. ${ }^{182627}$

\section{Conclusions}

It is important to note that this in situ hybridisation technique allows the identification of the target homologues in virtually every cell at all specific stages. Therefore, a direct quantitative analysis of such phenomena as gonadal mosaicism and first meiotic segregation of structural rearrangements as well as first meiotic non-disjunction of specific chromosomes can now be realised for the first time.

We are grateful to J W Gray, D Pinkel, and R Segraves of the Lawrence Livermore National Laboratory for their generous advice and the gift of the pBS series of whole chromosome libraries. We are grateful also to members of the Regional Genetics Services at East Birmingham Hospital for their general support in developing this project and to Mr Holl-Allen for performing the biopsies. This work was funded by L F Saugstad's research fund and a travel scholarship from the American Express Travel Agency.

1 Pinkel D, Straume T, Gray JW. Cytogenetic analysis using quantitative, high-sensitivity, fluorescence hybridization. quantitative, high-sensitivity, fluorescence
Proc Natl Acad Sci USA 1986;83:2934-8.

2 Lichter P, Cremer T, Borden J, Manuelidis L, Ward DC. Delineation of individual human chromosomes in metaphase and interphase cells by in situ suppression hybridization using recombinant DNA libraries. Hum Genet 1988;80:224-34.

3 Van Dilla MA, Deaven LL. Construction of gene libraries for each human chromosome. Cytometry 1990;11:208-18

4 Fuscoe JC, Clark LM, Van Dilla MA. Construction of fifteen human chromosome-specific DNA libraries from flow-purified chromosomes. Cytogenet Cell Genet 1986;43:79-86.

5 Pinkel D, Gray JW, Trask B, van den Engh G, Fuscoe J, van Dekken $\mathrm{H}$. Cytogenetic analysis by in situ hybridiza tion with fluorescently labelled nucleic acid probes. Cold Spring Harbor Symp Quant Biol 1986;51:151-7.

6 Kievits T, Devilee P, Wiegant J, et al Direct. active in situ hybridization of somatic cell hybrid DNA to human lymphocyte chromosomes. Cytometry 1990; 11:105-9.

7 Giacci AJ, Evans JW, Brown JM. Use of fluorescent in situ hybridization to detect chromosomal rearrangements in hybridization to detect chromosomal rearrangements in
somatic cell hybrids. Genes, Chromosomes and Cancer 1990;2:248-51.

8 Jauch A, Daumer C, Lichter P, Murken J, SchroederKurth T, Cremer T. Chromosomal in situ suppression hybridization of human gonosomes and autosomes and its use in clinical cytogenetics. Hum Genet 1990;85:145-50.

9 van Dekken H, Bauman JGJ. A new application of in situ hybridization: detection of numerical and structural chromosome aberrations with a combination centromerictelomeric DNA probe. Cytogenet Cell Genet 1988 48:188-9.

10 Cremer T, Lichter P, Borden J, Ward DC, Manuelidis L. Detection of chromosome aberrations in metaphase and interphase tumour cells by in-situ hybridization using chromosome-specific library probes. Hum Gene 1988;80:235-46.

11 Cremer T, Tesin D, Hopman AHN, Manuelidis L. Rapid interphase and metaphase assessment of specific chromosomal changes in neuroectodermal tumor cells by in situ 
hybridization with chemically modifed DNA probes. $\operatorname{Exp}$ Cell Res 1988;176:199-220.

12 Pinkel D, Lanlegent J, Collins C, et al. Fluorescence in situ hybridization with human chromosome-specific libraries: detection of 4. Proc Natl Acad Sci USA 1988;85:9138-42.

13 Cremer T, Popp S, Emmerich P, Lichter P, Cremer C. Rapid metaphase and interphase detection of radiationRapid metaphase and interphase detection of radiation-
induced chromosome aberrations in human lymphocytes by chromosomal suppression in situ hybridization. Cytoby chromosomal supp

14 Manuelidis L. Individual interphase chromosome domains revealed by in situ hybridization. Hum Genet 1985; 71:288-93.

15 Manuelidis L, Borden J. Reproducible compartmentalization of individual chromosome domains in human CNS cells revealed by in situ hybridization and three dimensional reconstruction. Chromosoma 1988;96:397-410.

16 Trask B, van den Engh G, Pinkel D, et al. Fluorescence in situ hybridization of interphase cell nuclei in suspension allows flow cytometric analysis of chromosome content and microscopic analysis of nuclear organization. Hum Genet 1988;78:251-9.

17 van Dekken H, Pinkel D, Mullikin J, Trask B, van den Engh G, Gray J. Three-dimensional analysis of the organization of human chromosome domains in human and human-hamster hybrid interphase nuclei. $f \mathrm{Cell} S c i$ 1989;94:299-306.

18 Wyrobek AJ, Alhborn T, Balhorn R, Stanker L, Pinkel D. Fluorescence in situ hybridization to $\mathrm{Y}$-chromosomes in decondensed human sperm nuclei. Mol Reprod Dev 1990;27:200-8.

19 Hultén M, Saadallah N, Wallace BMN, Creasy MR. Meiotic studies in man. In: Rooney DE, Czepuldouski BH, eds. Human cytogenetics. A practical approach. Oxford: IRL Press, 1986:163-96.

20 Hulten M, Lindsten J. The behaviour of structural aberrations at male meiosis: information from man. Fifth Pfizer International Symposium. Human Population Symp CytoInternational Symposium. Human Pop

21 Hultén M, Lindsten J. Cytogenetic aspects of human male meiosis. Adv Hum Genet 1973;23:230-40.

22 Holm PB, Rasmussen SW. Human meiosis III. Electron Holm PB, Rasmussen SW. Human meiosis 111 . Electron an individual with a balanced translocation 46,CY,t $(5 p-; 22 p+)$. Carlsberg Res Commun 1978 43:329-50.

23 Laurie DA, Firkett CL, Hultén MA. A direct cytogenetic technique for assessing the rate of first meiotic nonmetaphase II. Ann Hum Genet 1985;49:23-99.

24 Joseph AM, Gosden JR, Chandley AC Estimation of aneuploidy levels in human spermatozoa using chromoaneuploidy levels in human spermatozoa using chromo1984;66:234-8.

25 Burns J, Chan VTM, Jonasson JA, Fleming KA, Taylor S, McGee JOD. Sensitive system for visualising biotinylated DNA probes hybridized in situ. $\mathcal{f}$ Clin Patho 1985;38:1085-92.

26 Meyne J, Littlefield GL, Moyzis RK. Labelling of human centromeres using an alphoid DNA consensus sequence: application to the scoring of chromosome aberrations. Mutat Res 1988;226:75-9.

27 Eastmond DA, Pinkel D. Detection of aneuploidy-inducing agents in human lymphocytes using fluorescence in situ hybridization with chromosome-specific DNA probes. Mutat Res 1990;234:303-18. 